\title{
Application of the Rorschach test in psychological diagnosis of personality disorders
}

\section{BACKGROUND}

The paper presents the authors' own research, which points to the possibility of applying the Rorschach test in the clinical diagnosis of personality disorders.

\section{PARTICIPANTS AND PROCEDURE}

The clinical research was conducted in the years 20102013 in the Neurosis Treatment Center and in the Mental Health Outpatient Clinic. The study population comprised individuals with a medical diagnosis of neurotic personality organization as well as patients with more severely disorganized personality structure. The research participants had never undergone psychological evaluation for personality disorders (for instance, they had never taken the Rorschach test), and therefore it seemed rather difficult to verify the accuracy of the medical diagnoses which they had received, concerning the level of personality destabilization. Eighty Polish individuals participated in the research. The study population comprised 38 males $(47.50 \%)$ and 42 females $(52.50 \%)$. The mean age of women was 30.40 $(S D=7.67)$. The men's mean age was $35.10(S D=8.73)$. The examined females were somewhat younger than the male subjects. Methods: Rorschach test, clinical interview.

\section{RESULTS}

The statistical procedures applied in the present study allowed us to conduct empirical examination of the indicators of the investigated variables constituting the major psychological criteria for describing psychological functioning of personality, and thus to identify the main characteristics of neurotic as well as borderline level of personality organization. Analysis of the data obtained as a result of this research allowed us to distinguish two significantly different clusters in the group of 80 examined individuals.

\section{CONCLUSIONS}

The results of the present investigation indicate that despite the fact that the examined individuals displayed symptoms of different medical diagnoses (F40 and F60), the subjects comprising cluster 1 exhibited a higher level of personality structure compared with the study participants belonging to cluster 2 .

\section{KEY WORDS}

Rorschach test; psychological diagnosis personality disorders

ORGANIZATION - 1: Institute of Applied Psychology, Jagiellonian University, Krakow, Poland · 2: the "Dąbrówka" Neurosis and Eating Disorders Center, Gliwice, Poland

AUthors' CONTRibutions - A: Study design - B: Data collection - C: Statistical analysis - D: Data interpretation ·

E: Manuscript preparation F: Literature search G: Funds collection

CORRESPONDING AUTHOR - Prof. Bernadetta Izydorczyk, Institute of Applied Psychology, Jagiellonian University,

4 Łojasiewicza Str., 30-060 Krakow, Poland, e-mail: b.izydorczyk@interia.pl

TO Cite this ARTiCLE - Izydorczyk, B., \& Gąska, A. (2016). Application of the Rorschach test in a psychological diagnosis

of personality disorders. Health Psychology Report, 4(4), 340-359. doi: 10.5114/hpr.2016.59886

RECEIVED 24.09.2015 · REVIEWED 21.10.2015 · ACCEPTED 13.01.2016 · PUBLISHED 25.05.2016 


\section{BACKGROUND}

The present paper presents the results of the authors' own research, which point to the possibility of applying the Rorschach test in a clinical diagnosis of personality disorders. In contemporary psychiatry, personality disorders are defined and classified based on the criteria listed in two widely established systems: the Diagnostic and Statistical Manual of Mental Disorders (DSM-IV) and the International Statistical Classification of Diseases and Related Health Problems (ICD-10). There are nonetheless a number of limitations concerning application of universal and individual diagnostic criteria for various categories of personality psychopathology, and thus the medical diagnosis of these disorders proves to be least accurate in clinical practice (Grabski \& Gierowski, 2012).

Modern literature concerning clinical psychology provides examples of limitations regarding assessment of validity and reliability indicators of the projective methods applied in the process of investigation of psychological phenomena. However, the methods are often the only available tools that help to measure inner conflicts and experiences. It has to be emphasized that when examining a patient and making a diagnosis using projective methods, including the Rorschach test, a clinical psychologist is also obliged to assess the data obtained as a result of a clinical interview. Combining projective techniques with clinical ones determines accurate measurement of indicators of personality characteristics and dynamics, which in turn is necessary in selecting appropriate treatment for individuals with personality disorders.

Personality structure is commonly assessed be means of psychometric instruments, which include the Minnesota Multidimensional Personality Inventory (MMPI) (Paluchowski, 1984; Łuszczyńska-Cieślak \& Cieślak, 1996) and the NEO PI-R Inventory (Siuta, 2006; McCrae \& Costa, 2005); clinical methods (an interview, observation, or a clinical experiment; as well as projective techniques such as the Rorschach Inkblot Test (Stasiakiewicz, 2004; Czerederecka, 2006; Waszkiewicz \& Zakrzewska-Wirkus, 2012; Shafer, Erdberg, \& Meyer, 2007; Gacono \& Meloy, 1997). There are obviously proponents and opponents of applying the Rorschach technique for measuring a variety of internal experiences. Undoubtedly, it is one of the most difficult clinical diagnostic methods, and using it requires a vast knowledge of clinical psychology as well as considerable experience in administering this technique. Taking into consideration the limitations of projective methods, as well as the advantages of the inkblot test (the technique allows one to elicit information about the structure and dynamics of an individual's personality functioning, which is impossible to achieve with psychometric tests), some researchers finally responded to the considerable challenge and decided to use the Rorschach method in the studies conducted in individuals suffering from personality disorders. However, application of the technique required cooperation between an experienced clinical psychology specialist, a psychotherapist and a psychologist trained in administering the test and familiar with the Exner comprehensive scoring system. In 2005, after having been thoroughly examined by the Society for Personal Assessment (SPA), the Rorschach test was approved by the American Psychological Association (APA), which acknowledged it to be a scientifically proven psychometric instrument, and recommended applying it in clinical practice.

Despite the fact that it lacks validity and reliability, which has already been indicated in the present paper, the Rorschach test proves to be a legitimate method applied in a psychological diagnosis of various types of mental disorders, which is proven by research findings described in contemporary literature. It is not only the research studies conducted by Exner $(1974,1978,1986)$ that are worth mentioning but also other investigations carried out in various population groups and aimed at measuring indicators of mental disorders. Contemporary researchers addressing the aforementioned issue include the following:

- De Tichey (1982) and Chabert (1987), who, having applied the Rorschach test in their studies, highlighted the need to assess an individual's defense mechanisms in diagnosing borderline personality disorder;

- Di Nuovo (2000), who pointed to the legitimacy of using the Rorschach test in diagnosing borderline personality disorder;

- Diener, Hilsenroth, Shaffer, and Sexton (2011), who demonstrated the significance of the Rorschach test indicators in the process of examining mental disorders;

- Fellers (2012) in Canada, who applied the Rorschach test to measure the correlation between selected variables and neuroticism and extraversion;

- Bilash (2011), who measured empathy using indicators of the Rorschach test;

- Zodan, Hilsenroth, Charnas, Goldman, and Bornstein (2014), who demonstrated the significance of the Rorschach test in investigating the pattern of interpersonal relations and reality in individuals diagnosed with borderline personality disorder and those who have experienced sexual abuse;

- Xian-Zhang and Ting-Ye (2015), who applied the Rorschach test to measure Ego identity status in patients suffering from schizophrenia and in healthy individuals;

- Biagiarelli et al. (2015), who measured cognitive functions in psychotic patients using the aforementioned test.

Many researchers who employ the Rorschach test claim that assessment of defense mechanisms dis-
Application of Rorschach test in clinical diagnosis of personality disorders 
Bernadetta Izydorczyk, Agnieszka Gąska played by an individual proves to be an important criterion in the examination of the person's personality structure (De Tichey, 1982; Chabert, 1987). Following on from the works of Kernberg, Lerner et al. (1982, as cited in: Di Nuovo, 2000) developed a method of identifying indicators of defense mechanisms manifested in Rorschach responses. Application of the Rorschach test demonstrated that projective identification and dissociation are the most common defense mechanisms related to borderline personality organization. Dissociation was found to be frequently manifested by responses with contrary emotional connotations (e.g. in a sequence of responses: "two people who are fighting, and two people who are kissing”, or in two parts of the same reaction to an inkblot image: "the upper part of the giant seems to be good, and the bottom one is evil"); or by describing a positive image in a negative way and vice versa (e.g. "an ugly angel”, "a nice monster”). The mechanism of projective identification is revealed in situations when the inkblot images are interpreted and replaced by fantasies or emotional aspects (e.g. in confabulation responses), or when human content responses or those regarding humans are formulated, with aggressive connotations classified as passive or active (Di Nuovo, 2000).

Cooper, Perry, and Arnow (1988) developed a Rorschach scoring system for defense mechanisms. According to the researchers, individuals diagnosed with borderline personality disorder tend to display such defenses as dissociation, primitive idealization, omnipotence, and projective identification, whereas neurotic patients prove to use such defense mechanisms as intellectualization, reaction formation, or rationalization. There were also other researchers, such as Kwawer, Lerner, Lerner, and Sugarman (1980), as well as Gacono, Meloy, and Berg (1992), who highlighted the need to assess defense mechanisms and explore patterns of interpersonal relations using the Rorschach test in individuals with personality disorders.

The Rorschach test was also applied in the research conducted by Charnas, Hilsenroth, Zodan, and Blais (2010), aimed at measuring the effectiveness of psychodynamic psychotherapy in 101 drop-out patients. The Personality Assessment Inventory (PAI) and the Rorschach Inkblot Test were used to investigate differences between patients who withdrew early from outpatient psychodynamic psychotherapy and those who continued in treatment. Bram (2010) demonstrated a significant role of the Rorschach method in the process of making a psychological diagnosis and planning psychological therapy in a youth population.

It is a common occurrence that contemporary researchers in their attempts to measure personality characteristics and examine mental disorders (frequently personality disorders) utilize not only the Rorschach technique but also other psychological tests. A tendency to combine the Rorschach test and other instruments (e.g. the Minnesota Multidimensional Personality Inventory MMPI-2) in order to investigate psychological dysfunctions is observed among contemporary researchers, which can be illustrated by American studies conducted by Jordan (2012) in a population of 260 sexual offenders, aimed at investigating the issue of personality organization and sexual deviation (pedophile tendencies).

Taking into consideration the aforementioned research findings, it would seem that all the limitations regarding validity and reliability of the Rorschach test can be overcome by conducting further, comparative studies in different populations, and combing the Rorschach results and the data gathered using the MMPI-2 inventory, or the NEO-PI-R questionnaire, a psychological personality inventory intended to measure the Big Five personality traits, based on the DSM-IV system (Costa and McCrae, adapted into Polish by Siuta, 2006).

Moreover, it should be emphasized that such factors as large size of a study population and its considerable diversity in terms of personality disorders displayed by the subjects (e.g. borderline, histrionic, narcissistic, symbiotic, paranoid, or schizoid personality), as well as a wide range of personality characteristics examined using the Rorschach test, are likely to guarantee reaching valid and coherent conclusions concerning a map of specific indicators of personality disorders, which can be determined based on the results of a projective method and a clinical interview. The map may prove useful in developing appropriate treatment plans for patients diagnosed with personality disorders.

Exploring the world of inner conflicts and emotions, as well as assessing defensive mechanisms in individuals with personality disorders, using clinical together with projective methods, yields increasingly more reliable results since the techniques help to reduce the risk of response bias, i.e. the phenomenon of subjective, conscious and untruthful responses being provided by the study subjects, which seems to be the case in the situation when solely psychometric methods (including the MMPI-2 inventory) are applied. Hence, combining the Rorschach method and other techniques is likely to considerably facilitate the process of examining the clinical criteria which are significant in assessing the strength level of personality disorders.

Therefore, despite the fact that it lacks validity and reliability, the Rorschach test is an excellent and significant source of information concerning the structure and dynamics of an individual's personality functioning, which might prove helpful in facilitating effective psychotherapy for individuals exhibiting symptoms of various types of personality disorders. Stasiakiewicz (2004) points out that a configuration of personality indicators measured using the Ror- 
schach test allows one to determine directions and changes in the process of psychotherapy. The method for interpreting the Rorschach inkblot test, applied in the present study, was based on the Exner system of scoring, which was also used in Polish clinical studies (including those published in scientific peer-reviewed journals) conducted by Stasiakiewicz (2004) and Czerederecka (2006).

There are significant differences between objectives of a medical and psychological diagnosis in reference to individuals with personality disorders. This in turn triggers differences in terms of the main assumptions of each of the aforementioned types of diagnosis. The categories of personality disorders identified based on the criteria of a medical classification in ICD-10 or DSM-IV define specific sets of symptoms characteristic of specific types of personality disorders (regarded as disease entities). Thus a medical diagnosis provides general medical indications for treatment of a person exhibiting symptoms of a personality disorder, whereas a psychological diagnosis of personality disorders focuses on a structural approach to psychopathology; i.e. a diagnostic process involves assessing mechanisms of integration and adaptation (defense, adaptation mechanisms), examining the level of identity, reality testing, patterns of interpersonal relations and personality characteristics (such as empathy, the capacity to feel guilt or fear) of a patient exhibiting symptoms of a personality disorder, classified according to the criteria of ICD-10 or DSM- 5 as a disease.

The model of a clinical diagnosis applied in the present authors' own research focuses on examining indicators of two dimensions of personality structure: intrapsychic and interpersonal.

The criteria of the intrapsychic dimension include the following:

- level of maturity of the person's identity and reality testing - an appropriate level of the sense of self and others (the level of the person's cognitive and emotional identity, i.e. appropriate perception and experiencing boundaries in the process of perceiving oneself and the world; maintained capacity for self-observation and self-reflection; capacity to undertake purposeful actions; adequate self-evaluation),

- level of defense mechanisms (capacity for adequate modulation of emotions and drives in dealing with stress and inner conflicts, level of impulsive responsiveness and aggressive as well as self-aggressive behaviors),

- capacity to experience the feeling of guilt and commonly accepted social norms.

The criteria of the interpersonal dimension include the following:

- patterns of interpersonal relations (i.e. capacity to establish and maintain emotional bonds with other people; empathy - fundamental ability to recognize other people's inner experiences). The criterion describes positive and negative feelings experienced by a person in the context of establishing interpersonal relations. When being examined a subject tends to manifest his or her feelings by projecting them onto a diagnostician, which is in turn provokes counter-projection. The feelings include positive emotions (trust and lack of hostility towards a tester) as well as negative ones (excessive and inadequate withdrawal, anhedonia, timidity, insecurity, distrust, suspicion, hostility).

\section{PARTICIPANTS AND PROCEDURE}

\section{RESEARCH QUESTIONS AND OBJECTIVES}

This paper reports the research results which provide empirical evidence in support of the legitimacy of applying a clinical method and the Rorschach Inkblot Test in clinical practice for psychological diagnosis of personality disorders. Two research questions were asked:

1) Do the Rorschach test indicators allow one to identify the specific characteristics of personality disorders in the population of the examined individuals diagnosed with various types of neurotic disorders (classified according to the criteria included in the ICD-10 and diagnosed as categories F40-F41) or personality disorders (according to the ICD-10: F60)?

2) Are there any differences between the study participants in terms of the configuration of the major clinical indicators describing the organization of the subjects' personality structure? Are their personalities organized at the neurotic level, or is the organization of their personality structure more destabilized, which according to the psychodynamic approach suggests a borderline level of personality organization? If there are such differences, what are the characteristics of these configurations, and what makes them different?

\section{RESEARCH SUBJECTS AND PROCEDURES}

The clinical research was conducted in the years 2010-2013 in the Neurosis Treatment Center and in the Mental Health Outpatient Clinic. Due to the issues addressed in this study, the subjects were selected intentionally, based on their medical history and the kind of outpatient psychotherapy they had been receiving. The study population comprised individuals with a medical diagnosis of neurotic personality organization as well as patients with more severely disorganized personality structure. Neurotic tendencies are believed to manifest themselves as anxiety disorders, whereas personality disorders (classified
Application of Rorschach test in clinical diagnosis of personality disorders 
Bernadetta Izydorczyk, Agnieszka Gąska according to the ICD criteria as F60) are likely to be symptomatic of more severe destabilization of personality structure, which according to the psychodynamic approach presented by Gabbard points to high- or low-level borderline organization of personality structure (2009). However, McWilliams (2010) defines it as borderline or psychotic personality.

The research participants had never undergone psychological evaluation for personality disorders (for instance, they had never taken the Rorschach test), and therefore it seemed rather difficult to verify the accuracy of the medical diagnoses which they had received, concerning the level of personality destabilization.

Eighty Polish individuals participated in the research. The study population comprised 38 males (47.50\%) and 42 females $(52.50 \%)$. The mean age of women was $30.40(S D=7.67)$. The men's mean age was $35.10(S D=8.73)$. The examined females turned out to be somewhat younger than the male subjects. The selection criteria included symptoms of medically diagnosed disorders classified as F40-F41 and F60 (according to the ICD-10 criteria). Forty research participants (50\%) were medically diagnosed with neurotic disorders such as panic anxiety syndrome (20 individuals $-25 \%$ of the study sample) or generalized anxiety syndrome (20 subjects $-25 \%$ of the study population). Forty individuals had a medical diagnosis of F60 (according to the ICD-10 classification criteria).

The criteria which excluded participation in the research included: symptoms of mental retardation; productive psychotic symptoms; organic changes in the central nervous system (CNS); symptoms of medically diagnosed psychosomatic diseases (cancer); lack of motivation to undertake therapy (treatment under compulsion without the patient's consent); unstable motivation, often referred to as feigned, which is characteristic of the attitude aimed at "secondary gain", i.e. the subsequent benefit that a patient may derive from being in the sick role, feeling no need to change his or her own inner (psychological) functioning.

The research was conducted according to the principle of anonymity. Informed consent was obtained from all study participants.

\section{RESEARCH METHODS}

In order to establish the basic criteria for the selection of appropriate methods of further treatment for the "Dąbrówka" patients suffering from various psychopathologies, the examined individuals underwent a general clinical evaluation (the methods included an interview, observation and a psychological conversation). Additionally, the Rorschach Inkblot Test, which aimed at measuring the indicators describing the characteristics of the subjects' personality struc- ture, was administered to the research participants. The aforementioned methods are significant tools which are commonly applied to measure psychological characteristics and personality functioning. Other measurement instruments (e.g. the MMPI) were unavailable during the present study. Due to limitations arising from the lack of Polish norms of the aforementioned tool, it was not applied in the current research.

\section{RESULTS}

Statistical analysis of the data obtained as a result of this research, aimed at answering the questions addressed in the present investigation, was performed. The arithmetic mean was chosen as a measurement of the central tendency in the study data set. It was used to measure the strength level of all indicators of the examined variables. Analysis of the overall data concerning indicators of the investigated variables was performed using the k-means method, which was aimed at detecting any possible similarities and differences between the research subjects. The statistical procedures applied in the present study allowed us to conduct empirical examination of the indicators of the investigated variables constituting the major psychological criteria for describing psychological functioning of personality, and thus to identify the main characteristics of neurotic as well as borderline level of personality organization. Based on this classification, it was possible to establish preliminary diagnostic criteria that could be applied in psychodynamic psychotherapy for the individuals suffering from personality disorders, undergoing outpatient treatment in the "Dąbrówka" Neurosis and Eating Disorders Center in Gliwice, which was described in a separate paper presenting a model of diagnostic criteria applicable in psychodynamic psychotherapy for individuals exhibiting symptoms of personality disorders (Izydorczyk \& Gąska, 2015).

Analysis of the data obtained as a result of this research allowed us to distinguish two significantly different clusters in the group of 80 examined individuals. A graphic illustration of the gathered data is presented in Figure 1. The clusters which were homogeneous in terms of the strength level and the configuration of the indicators describing the characteristics of personality structure were not displayed in the figure below.

The research data illustrated in Figure 1 reveal significant differences between the examined 80 individuals in terms of the configuration of the indicators of the investigated variables. Cluster 1 comprised 30 subjects, and 50 research participants constituted cluster 2 .

Analysis of the medical history of the research subjects revealed that 17 individuals comprising clus- 


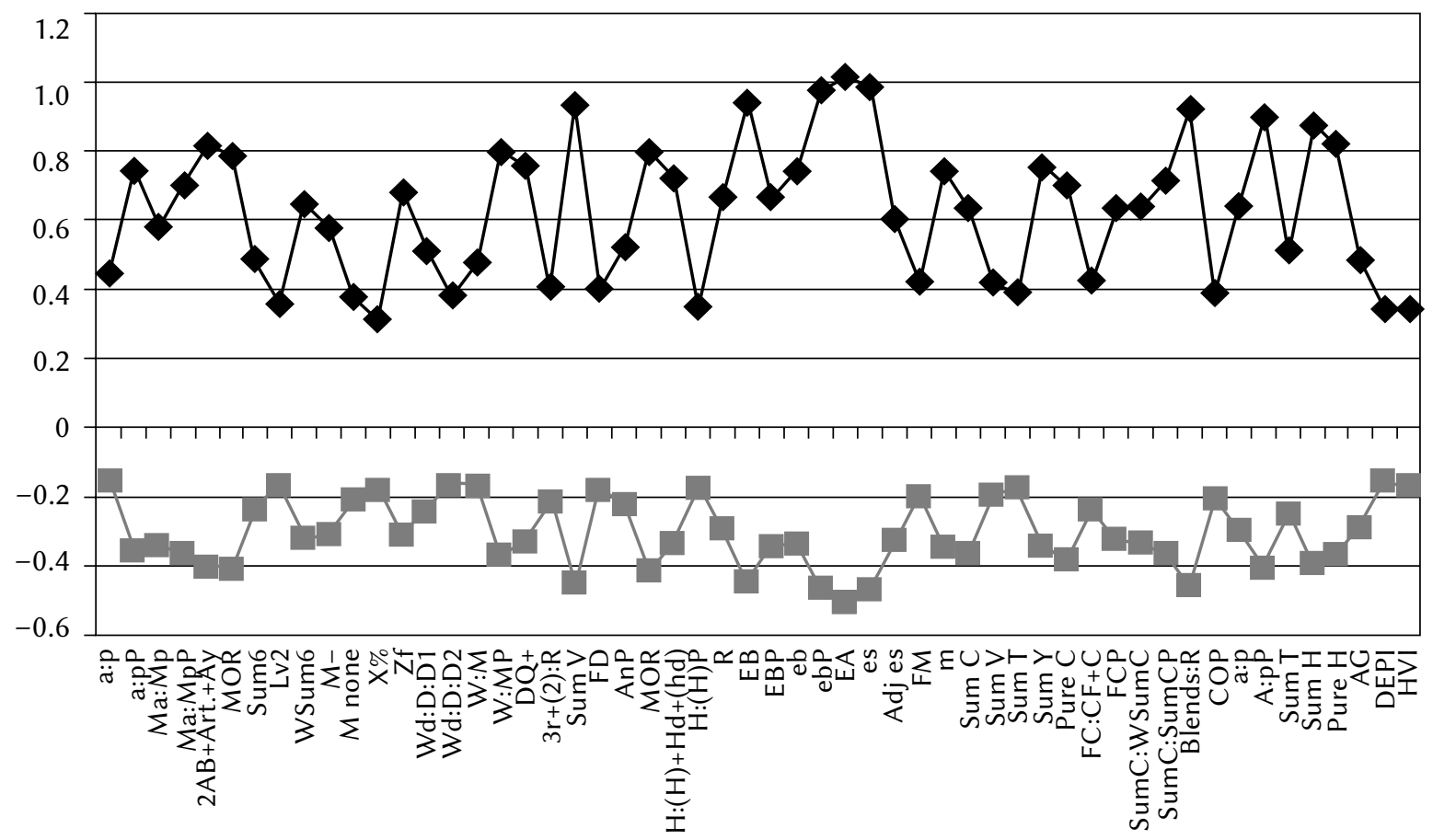

Application of Rorschach test in clinical diagnosis of personality disorders

Rorschach test' indicators

$\neg$ Cluster $1 \multimap-$ Cluster 2

Figure 1. Graphic illustration of cluster analysis conducted using the k-means method. Specification of intragroup differences in terms of the investigated indicators describing the configuration of personality structure characteristics within the study population $(N=80)$.

ter $1(21 \%)$ exhibited neurotic symptoms (according to the ICD-10 F40-F41 criteria of psychiatric classification); and 23 individuals in this cluster were medically diagnosed with personality disorders classified as category F60 (according to the ICD-10 classification).

Cluster 2 comprised 32 individuals with medical diagnoses of personality disorders classified as F60 category (40\% of the study population) and 23 subjects displaying symptoms of medically diagnosed neurosis (according to the ICD-10 F40-F41 criteria of psychiatric classification).

The data obtained as a result of this research indicated that both clusters comprised individuals exhibiting neurotic symptoms (F40-F41) as well as subjects suffering from personality disorders (F60). However, cluster 1 was found to be dominated by individuals diagnosed with personality disorders classified as category F60 (according to the ICD classification), whereas in cluster 2 the proportions of neurotic patients and the subjects revealing symptoms of personality disorders were similar. It was also discovered that cluster 2 was larger than cluster 1 .

The results of cluster analysis also indicated that the two subgroups of study subjects revealed significant differences in terms of the configuration of the major characteristics of personality structure, which were assessed using the Rorschach test.
Fisher's exact test for two independent samples was used to compare the differences between the two examined clusters in terms of the investigated psychological variables and their indicators. The method allowed us to distinguish two different configurations of psychological variables describing the main characteristics of intrapsychic and interpersonal dimension of personality functioning in the 80 examined individuals. Two different types of psychological functioning were distinguished among the study subjects comprising the two clusters.

Table 1 presents the data concerning the configuration of indicators of the intrapsychic dimension of personality structure, which were obtained in clusters 1 and 2 .

Analysis of the data obtained as a result of this research indicates that the subjects comprising cluster 1 and cluster 2 are identified as ambitent. This proves that the examined individuals tend to make decisions and evaluate the world based on their reflections and emotions, as well as on the information which they derive from the surrounding (social) environment. It is also likely that the subjects find it difficult to make choices and decisions, and they are inclined to hesitate, which significantly decreases their processing efficiency. The low number of $\mathrm{M}$ responses in both clusters proves that the subjects' mode of thinking cannot be interpreted as conceptual. It was also found that 
Table 1

Mean values regarding indicators of personality structure (the intrapsychic dimension), obtained in cluster 1 $(n=30)$ and cluster $2(n=50)$. Results of analysis of variance (ANOVA) and Fisher's exact test for two independent samples

\begin{tabular}{lcc}
\hline $\begin{array}{l}\text { Indicators of personality structure } \\
\text { (intrapsychic dimension) }\end{array}$ & $\begin{array}{c}M^{*} \\
\text { Cluster 1 } \\
(n=30)\end{array}$ & $\begin{array}{c}\text { Cluster 2 } \\
(n=50)\end{array}$ \\
\hline
\end{tabular}

Intrapsychic dimension - self-structure characteristics and the level of identity maturity exhibited by the examined individuals

Bernadetta Izydorczyk,

Level of cognitive and emotional maturity of the subject's identity - the person's capacity to think appropriately and recognize the boundaries the self and the world

a:p (1 Flexibility of thinking, behavior and attitudes index)

a:p (2 Flexibility of thinking, behavior and attitudes index)

$0.45(5.84)^{*}-0.15(3.49)^{*} \quad 6.20 \quad .015$

Ma:Mp (1 index of independent and conceptual thinking)

$0.74(7.28) \quad-0.35(4.04) \quad 25.71 \quad .001$

Ma:Mp (2 index of independent and conceptual thinking)

$0.58(3.12) \quad-0.34(1.41) \quad 19.90 \quad .001$

$2 \mathrm{AB}+$ Art. $+\mathrm{Ay}$ (intellectualization index - intellectualizing

$0.71(3.40) \quad-0.36(1.71) \quad 24.23$

.001

as a defense mechanism)

MOR (index of the sense of adversity, harm and discomfort)

$0.82(7.48) \quad-0.40(3.11) \quad 33.81 \quad .001$

Sum6 (distorted thinking index)

$0.79(5.00) \quad-0.41(1.91) \quad 32.46 \quad .001$

$\begin{array}{llll}0.49(3.96) & -0.23(2.05) & 9.03 \quad 004\end{array}$

Lv2 (distorted thinking index)

WSum6 (distorted thinking index)

$M$ - (index of bizarre thoughts and delusions)

$0.36(1.12) \quad-0.17(0.33) \quad 4.65 \quad .034$

$0.65(16.28)-0.32(4.70) \quad 18.15 \quad .001$

$0.58(1.68) \quad-0.31(0.55) \quad 14.86 \quad .001$

$M$ none (index of the likelihood of delusions)

$0.38(0.52) \quad-0.21(0.11) \quad 6.21$

.015

Self-perception and evaluation of the world

XA\% (adequate responses - not distorted) - index of adaptive perception of the world in accordance with the expectations of the social environment - reality testing index

WDA\% responses referring to the space of the whole card and to undistorted details) - coping capacity index

$\mathrm{X} \%$ (\% of responses that have distorted form quality) - distorted perception index)

$\mathrm{S} \%$ white space distortion)

$\begin{array}{llll}-0.25(65.72) & 0.15(71.69) & 2.63 \quad .109\end{array}$

$\mathrm{P}$ - index of popular, conventional responses, which indicates the subject's capacity for conventional perception,

and the individual's ability to conform to the established norms and conventions

$X+\%$ (common responses that have conventional form

Xu\% (\% uncommon responses that have unconventional form quality) - index of unconventional but appropriate responses

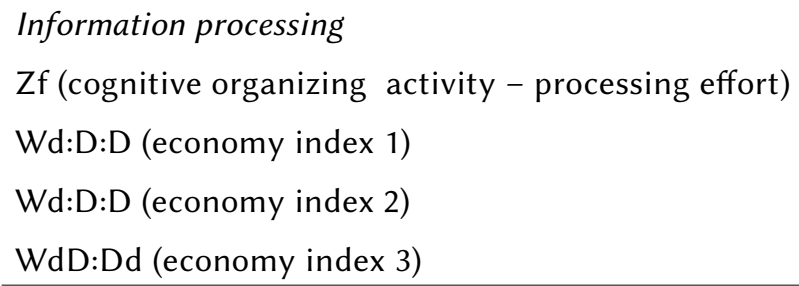


Table 1

(Table 1 continued)

\begin{tabular}{|c|c|c|c|c|}
\hline $\begin{array}{l}\text { Indicators of personality structure } \\
\text { (intrapsychic dimension) }\end{array}$ & $\begin{array}{c}M^{*} \\
\text { Cluster } 1 \\
(n=30) \\
\end{array}$ & $\begin{array}{c}M \\
\text { Cluster } 2 \\
(n=50) \\
\end{array}$ & $F$ & $p$ \\
\hline $\begin{array}{l}\text { W:M } 1 \text { (aspirational ratio - balance between achievement } \\
\text { of goals and cognitive ability) }\end{array}$ & $0.48(9.76)$ & $-0.17(6.31)$ & 7.50 & .008 \\
\hline $\begin{array}{l}\text { W:M } 2 \text { (aspirational ratio - balance between achievement } \\
\text { of goals and cognitive ability) }\end{array}$ & $0.80(6.00)$ & $-0.379(2.54)$ & 29.95 & .001 \\
\hline
\end{tabular}
of goals and cognitive ability)

Zd (processing efficiency index)

$\begin{array}{llll}-0.06 & (-0.24) \quad 0.02(0.60) & 0.11 \quad .741\end{array}$

PSY (perseveration, distorted perception: difficulty in shift- $\quad-0.23(0.84) \quad 0.11(1.20) \quad 1.94 \quad .168$

ing a cognitive set)

$\mathrm{DQ}+$ index of complex intellectual activity, or complex cognitive processing index - intellectual efficiency, organized synthetic activity)

Dqv (distorted and vague perception index )

$0.19(2.68) \quad-0.07(2.00) \quad 1.12 \quad .294$

\section{Self-Esteem}

$3 r+(2): R$ (egocentricity index - a measure of self-esteem)

$0.41(0.42) \quad-0.21(0.32) \quad 6.66 \quad .012$

$\mathrm{Fr}+\mathrm{rF}$ (narcissistic tendencies)

$\begin{array}{llll}0.21(0.64) & -0.10(0.38) & 1.66 & .202\end{array}$

Sum V (self-criticism and a sense of guilt)

$0.93(1.28) \quad-0.45(0.18) \quad 51.28 \quad .001$

FD (introspective capacity - the ability to exercise self-control, postponement and self-reflection)

$0.40(2.48) \quad-0.18(0.51) \quad 5.72 \quad .019$

$A n+X y: R A n+X y: R$ (preoccupation with body vulnerability index 1)

$0.07(2.64) \quad-0.05(2.44) \quad 0.22 \quad .643$

An (preoccupation with body vulnerability index 2)

$0.53(18.80)-0.22(9.35) \quad 10.05 \quad .002$

MOR (sense of adversity and harm)

$0.80(4.52) \quad-0.41(1.18) \quad 34.66 \quad .001$

$\mathrm{H}:(\mathrm{H})+\mathrm{Hd}+(\mathrm{hd})-$ perception of self, others and relationships with other people

$\mathrm{H}:(\mathrm{H})$ (attitudes to other people - self-evaluation and views of other people)

$\begin{array}{llll}0.72(4.16) & -0.34(1.95) & 23.94 & .001\end{array}$

$0.35(5.44) \quad-0.18(3.64) \quad 4.64 \quad .034$

Stress tolerance and emotion control

$\mathrm{R}$ (the total number of responses) emotion control

EB (experience style 1): ambitent, introvert-extravert

$\begin{array}{llll}0.67(26.96) & -0.29(20.09) & 18.43 \quad 001\end{array}$

EB (experience style 2): ambitent, introvert-extravert

$0.94(6.40) \quad-0.44(2.41) \quad 52.05 \quad .001$

$\begin{array}{llll}0.67(6.54) & -0.34(3.20) & 20.84 \quad .001\end{array}$

eb (demand for stimulation : aspiration - response inhibition 1)

$0.74(7.76) \quad-0.34(4.57) \quad 25.71 \quad .001$

eb (demand for stimulation : aspiration - response inhibition 2)

$0.97(6.98) \quad-0.47(2.15) \quad 59.53 \quad .001$

$\mathrm{L}$ (lambda) responsiveness to stimuli, a capacity to act in accord with the needs and demands of the social environment

EA (conscious organization of experience - level of integration of the person's inner life; strength, identity maturity)

es (experienced stimulation)

$\begin{array}{llll}1.02(12.32) & -0.50(5.76) & 74.97 & .001\end{array}$

D (stress tolerance and a current capacity to control life)

$0.99(13.76) \quad-0.47(6.20) \quad 63.04 \quad .001$

$\begin{array}{llll}0.18(1.88) & -0.10(0.19) & 1.20 \quad .277\end{array}$

(Table 1 continues) 
Table 1

(Table 1 continued)

\begin{tabular}{|c|c|c|c|c|}
\hline $\begin{array}{l}\text { Indicators of personality structure } \\
\text { (intrapsychic dimension) }\end{array}$ & $\begin{array}{l}M^{*} \\
\text { Cluster } 1 \\
(n=30)\end{array}$ & $\begin{array}{l}M \\
\text { Cluster } 2 \\
(n=50)\end{array}$ & $F$ & $p$ \\
\hline $\begin{array}{l}\text { Adj D (capacity to control one's behavior - after removing } \\
\text { environmental stressors) }\end{array}$ & $0.28(2.92)$ & $-0.13(0.33)$ & 2.65 & .108 \\
\hline $\begin{array}{l}\text { FM (realization of unwanted aspirations in response to con- } \\
\text { scious impulses) }\end{array}$ & $0.42(5.88)$ & $-0.20(2.70)$ & 6.63 & .012 \\
\hline $\begin{array}{l}\text { M a capacity to internalize experiences, the level of concep- } \\
\text { tual thinking }\end{array}$ & $0.74(3.36)$ & $-0.34(1.46)$ & 25.51 & .001 \\
\hline $\begin{array}{l}\text { Sum C emotional modulation index: the blocking mecha- } \\
\text { nism -impulsive expression of emotions) }\end{array}$ & $0.64(2.28)$ & $-0.37(0.89)$ & 21.79 & .001 \\
\hline $\begin{array}{l}\text { Sum V (self-esteem index: index of the feeling of guilt, } \\
\text { painful emotions related to introspection, and negative } \\
\text { self-regard) }\end{array}$ & $0.42(2.36)$ & $-0.19(0.26)$ & 6.45 & .013 \\
\hline $\begin{array}{l}\text { Sum T (index of empathy, the need to be liked, the ability } \\
\text { to express and accept warm feelings, the need for close } \\
\text { attachment with other people) }\end{array}$ & $0.39(1.88)$ & $-0.18(0.24)$ & 5.43 & .023 \\
\hline Sum Y (anxiety and helplessness index, lack of coping & $0.75(2.68)$ & $-0.34(0.50)$ & 25.58 & .001 \\
\hline
\end{tabular}

Bernadetta Izydorczyk, Agnieszka Gąska capacity)

Affect (emotional relationships, defense mechanisms)

Pure C (lack of capacity for emotional control, impulsive expression of emotions)

$\mathrm{FC}: \mathrm{CF}+\mathrm{C}$ emotion self-modulation

FC (emotion self-modulation: a capacity for emotional control - investing much effort in concealing emotions increased FC index).

SumC:WSumC (withdrawal - concealing emotions 1)

SumC:SumC (withdrawal - concealing emotions 2)

Afr (engaging in affectively charged situations)

$\mathrm{S}$ (opposing response index)

Blends:R (complexity of inner life - emotional maturity)

Blends:P (index of inner life complexity - emotional maturity index )

CP (a tendency to replace the feeling of helplessness with unjustified positive emotional responses which have no real grounds)

\section{Special indices}

PTI (distorted perception and thinking - indicator of the current psychotic process)

DEPI (depression index)

$0.70(2.72) \quad-0.38(1.07) \quad 25.94$

.001

$0.42(2.52) \quad-0.24(1.45) \quad 8.02 \quad .006$

$0.64(3.74) \quad-0.32(1.78) \quad 18.99 \quad .001$

CDI (coping deficit index)

$\begin{array}{rrrr}0.64(2.36) & -0.33(1.08) & 19.33 & .001 \\ 0.71(5.62) & -0.36(2.92) & 25.00 & .001 \\ -0.26(0.16) & 0.12(0.54) & 2.35 & .129 \\ 0.28(3.04) & -0.10(2.37) & 2.38 & .127 \\ 0.92(7.44) & -0.46(2.70) & 51.03 & .001 \\ 0.21(18.36) & -0.09(15.08) & 1.50 & .225\end{array}$

$0.17(0.13) \quad-0.06(0.06) \quad 0.84 \quad .361$

S-Con (suicide constellation and self-destructive acts)

$\begin{array}{rrrr}0.34(1.48) & -0.14(0.80) & 3.91 & .052 \\ 0.34(4.08) & -0.15(3.47) & 3.97 & .050 \\ -0.11(2.52) & 0.03(2.73) & 0.33 & .570 \\ 0.25(4.96) & -0.12(4.33) & 2.15 & .150 \\ 0.35(0.68) & -0.16(0.13) & 4.30 & .040\end{array}$

Note. *Arithmetic mean values for all indicators of intrapsychic dimension of personality structure examined in the present study are given in brackets. Figures outside brackets denote the weighted average values calculated for the aforementioned variables. 
the intellectualization score of the subjects in cluster 2 was within the expected range, but it was $50 \%$ lower than that of the individuals comprising cluster 1 , which proves that the latter group more often tends to resort to intellectualization as a defense strategy that involves postponing emotional responses and distancing oneself from anxiety-provoking emotions. It was discovered that the patients comprising cluster 2 were also lower on the MOR index (index of the sense of adversity, harm and discomfort), which indicates that they exhibit a reduced tendency towards pessimistic thinking and holding a negative view of the self and others. Moreover, they were found to make fewer thinking errors compared with the subjects belonging to cluster 2 . The data analysis revealed that the individuals comprising cluster 1 demonstrated a potential capacity for creative thinking, internalizing their experiences as well as taking thoughtful and well-organized actions.

The MOR index in cluster 1 suggests that the examined individuals in this sample, in contrast to the subjects in cluster 2, exhibit an inclination towards intellectualization as well as a tendency towards negative evaluation of the self and the surrounding reality, which is often accompanied by a strange and unusual character.

\section{CHARACTERISTICS OF PERCEPTION PROCESS}

Analysis of the research data concerning the dominant characteristics of the perception process exhibited by the examined individuals revealed significant differences between cluster 1 and cluster 2 . The subjects comprising cluster 2 were discovered to have significantly higher scores for the index of realistic perception of the world and cognitive reality testing, compared with the examined patients in cluster 1 , which proves that the individuals exhibit a capacity for more realistic perception of the world. However, when compared to healthy individuals, the subjects in cluster 2 had lower scores for cognitive reality testing, which indicates the presence of the mode of thinking and perceiving which is commonly interpreted as unusual and unconventional.

The patients belonging to cluster 1 scored slightly below the norm on the aforementioned variable, which denotes less realistic perception and significant distortions in thought processes. This in turn leads to perceptual inaccuracy, inappropriate evaluation of the self and reality deformation.

\section{CHARACTERISTICS OF INFORMATION PROCESSING}

The data obtained as a result of this research would seem to suggest that the examined patients in clus- ter 2 exhibit a decreased level of motivation for complex cognitive processing. The score in cluster 1 was within the expected range. The mean values of other indicators of perception efficiency point to the presence of slight perceptual distortions in the examined individuals comprising cluster 2, and to the lack of such distortions in cluster 1 . Significant differences were also found between the subjects in clusters 1 and 2 in terms of the mean value of $\mathrm{DQ}+$ (index of complex intellectual activity), which is another indicator of perception efficiency. The mean value of $\mathrm{DQ}+$ obtained in cluster 1 was within the expected normal range. The subjects in cluster 2 scored in the lower limit of the normal range, which turned out to be a worse result than that obtained by the individuals belonging to cluster 1 . From the figures it is apparent that the study participants comprising cluster 2 demonstrate an appropriate perceptual capacity, but the subjects in cluster 1 possess the capacity for more accurate perception.

It was also found that the study participants comprising cluster 1 exhibited a higher level of motivation for undertaking intellectual effort aimed at processing situation stimuli, compared with the subjects in cluster 2. Moreover, the individuals' cognitive effort seemed to be more effective. From these facts it can be assumed that the examined patients in cluster 1 are likely to set goals that are within reach, and match aspirations to their capacities.

Summing up, analysis of the data obtained using the Rorschach test, concerning all indicators of intellectual functioning in neurotic individuals as well as patients with personality disorders who comprised both study samples, revealed a higher level of intellectual efficiency in the subjects belonging to cluster 1. The findings of this study suggest that the individuals in cluster 1 exhibit a higher level of perception and thinking processes, compared with the study participants diagnosed with personality disorders belonging to cluster 2 .

Analysis of the data concerning the aforementioned indicators of cognitive and emotional maturity of identity and intellectual efficiency in the examined individuals indicates that the subjects comprising cluster 1 display characteristics which are symptomatic of a neurotic level of personality organization, whereas the individuals in cluster 2 prove to be organized at a high borderline level (according to Gabbard's classification).

\section{ASSESSMENT OF SELF-ESTEEM AND CHARACTERISTICS OF MORAL NORMS (THE CAPACITY TO EXPERIENCE AN ADEQUATE SENSE OF GUILT)}

The mean values of the indicators providing information about how the study participants view them-
Application of Rorschach test in clinical diagnosis of personality disorders 
Bernadetta Izydorczyk, Agnieszka Gąska selves, which are presented in Table 1, indicate that the individuals comprising cluster 1 maintain more adequate self-esteem, compared with the subjects belonging to cluster 2 . The values obtained in the self-esteem index in cluster 2 were within the norm; however, they were significantly lower than in cluster 1 . The data suggest that the level of self-esteem in the examined individuals in cluster 2 was lower than that in the subjects belonging to cluster 1 . In cluster 2 , the introspection index reached the value of 0 , which proves that the examined individuals in this sample have no interest in introspection, and they display no tendency towards gaining insight into their experiences and behaviors, as a consequence of which the examined individuals exhibit a decreased capacity for experiencing guilt. The study data prove that the subjects in cluster 2 show a lower tendency towards negative self-regard, compared with the individuals belonging to cluster 1 . It was also found that they display no prevailing tendency towards modifying their self-esteem based on individual experiences. The mean value of the self-esteem index obtained in cluster 1 was found to be within the expected normal range, which indicates that the study subjects comprising the sample maintain adequate self-esteem. The mean value of the narcissism index obtained in cluster 1 did not reach the value of 1 or above, which denotes lack of narcissistic personality disorder symptoms in the examined individuals. However, the value of the Sum V indicates that the subjects' sense of guilt causes discomfort and consequently negatively affects their self-esteem. Instead of stimulating change, the feeling of guilt and discomfort triggers ego defense mechanisms. Such individuals frequently make attempts at improving their self-esteem (maintaining positive self-evaluation) by offloading their guilt onto others. The mean value of the introspection index obtained in cluster 1 indicates that the study subjects comprising this sample tend to gain insight into their experiences and behaviors, but the process seems to be inadequate due to thinking distortions. The value of the MOR index suggests that the study participants belonging to cluster 1 have negative self-esteem and an increased sense of adversity and harm, accompanied by negative self-regard. The individuals seem to develop their self-esteem based on some unreal expectations and ideas rather than on their own experiences.

\section{CHARACTERISTICS OF EMOTIONAL CONTROL AND STRESS TOLERANCE}

Analysis of the data gathered as a result of this research revealed that the examined individuals comprising cluster 2 were higher on the Lambda (L) index in comparison with the subjects in cluster 1 , which denotes lower responsiveness to stimuli in this group of study participants. Moreover, the L score suggests that the subjects in cluster 2 are likely to adopt a conservative attitude towards reality and tend to accomplish their objectives, investing no emotional effort in it. The L score indicates that the individuals belonging to cluster 2 are task-oriented, and demonstrate preference for clear and definite situations. The EA index, indicating the individuals' capacity for conscious organization of inner experiences, had a value below the normal range, and was significantly lower than that obtained in cluster 1 . This indicates that the subjects comprising cluster 2 exhibit a lower level of emotional maturity, a decreased degree of organization of inner life, and an inclination towards impulsive behaviors in response to lack of adequate emotional resources. It seems that their emotional balance is feigned and can easily be disturbed. The score also points to the subjects' decreased awareness of impulses and indicates the presence of unwanted aspirations and unsatisfied needs. The data also reveal that when compared to the study participants in cluster 1 , the individuals comprising cluster 2 are less likely to experience inner tension, and they seem to exhibit a decreased level of anxiety as well as a lower empathic capacity.

The data gathered as a result of this investigation revealed that the examined patients belonging to cluster 2 exhibited difficulties in showing emotional responses. A tendency towards impulsive, barely controllable expression of emotions was detected among the study subjects comprising both samples. The examined individuals comprising cluster 2 were found to exhibit difficulties in showing warm and empathic feelings, which consequently leads to difficulties in coping with complex situations and triggers impulsive emotional responses. It was found that the examined individuals in cluster 2 tend to engage in situations stimulating emotional responses, which together with difficulties in modulating emotions seems to suggest that the subjects are unaware of their own problems. The value of DEPI (depression index), which was found to be lower than that obtained in cluster 1, proves that the study participants in cluster 2 are less likely to exhibit depressive tendencies, compared with the individuals comprising cluster 1 .

In contrast to the examined patients in cluster 2, the subjects belonging to cluster 1 demonstrated a stronger inclination towards withdrawal in response to strong emotional stimuli; they proved to be more aware of their own experiences and seemed to feel the need for situational control. The value of the Blends index in cluster 1 was higher than that in cluster 2, which is likely to point to a higher degree of complexity of emotional_life in the subjects comprising the sample, whereas the value of the DEPI index obtained in this group suggests that the individuals 
in cluster 1 are more likely to experience depressive episodes, compared with the subjects belonging to cluster 2 .

Taken together, the aforementioned study results suggest that the subjects comprising cluster 1 demonstrate a higher capacity to maintain adequate self-esteem, control emotions and cope with stress than the examined individuals in cluster 2. It was also observed that the study participants comprising cluster 1 display the characteristics which are symptomatic of a neurotic level of personality organization, whereas the individuals in cluster 2 were found to be organized at a high borderline level (according to the psychodynamic approach represented by Gabbard).

Table 2 illustrates the data concerning a configuration of the variables describing the characteristics of the interpersonal dimension of personality structure, obtained in clusters 1 and 2 .

\section{CHARACTERISTICS OF INTERPERSONAL FUNCTIONING (INTERPERSONAL PERCEPTION AND BEHAVIOR - SOCIAL INTERACTIONS)}

Significant differences were detected between the subjects in cluster 1 and the study participants belonging to cluster 2 in terms of the scores of the cooperation index (COP) and aggression index (AG). The individuals in cluster 2 scored lower on cooperation responses. The proportion of cooperation responses to aggression ones in both study samples suggests that the examined individuals in cluster 2 do not regard their interpersonal relations as positive. What is more, they do not expect to establish positive relationships with other people. The subjects seem to exhibit a lower capacity for cooperation, and are likely to feel insecure when entering relationships with other people. Consequently, they tend to distance themselves from others, which is illustrated by the lower value of the empathy index in this study sample, compared with that obtained in cluster 1 . In comparison with the individuals comprising cluster 1 , the subjects in cluster 2 seem to be less interested in social life; they have unrealistic expectations of others, which are rarely met in real life. The value of the isolation index obtained in this sample indicates that the examined individuals in cluster 2 are more likely to experience social alienation than the subjects in cluster 1.

It was found that when compared to the individuals comprising cluster 2 , the study participants in cluster 1 exhibit a greater tendency towards perceiving the social environment as aggressive, and they are more likely to display aggressive behaviors. However, the subjects also prove to be capable of expressing warm and empathic feelings. The research data also reveal that the individuals in cluster 1 , as opposed to the study participants belonging to cluster 2, demonstrate the need for immature dependence on other people's decisions. The subjects are interested in social life, they do not exhibit a tendency towards self-isolation, and their expectations of others

\section{Table 2}

Mean values regarding indicators of personality structure (the interpersonal dimension), obtained in cluster 1 $(n=30)$ and cluster $2(n=50)$. Results of analysis of variance (ANOVA) and Fisher's exact test for two independent samples

\begin{tabular}{|c|c|c|c|c|}
\hline $\begin{array}{l}\text { Indicators of personality structure } \\
\text { (interpersonal dimension) }\end{array}$ & $\begin{array}{c}M \\
\text { Cluster } 1 \\
(n=30)\end{array}$ & $\begin{array}{c}M \\
\text { Cluster } 2 \\
(n=50)\end{array}$ & $F$ & $p$ \\
\hline \multicolumn{5}{|l|}{ Interpersonal perception and behavior } \\
\hline COP (cooperative interaction index) & $0.39(1.72)^{*}$ & $-0.20(0.96)$ & 5.88 & .018 \\
\hline $\begin{array}{l}\text { Food (index of immature - childish dependency } \\
\text { orientation) }\end{array}$ & $0.31(1.28)$ & $-0.13(0.24)$ & 3.22 & .077 \\
\hline Sum T (empathy index) & $0.51(1.20)$ & $-0.25(0.30)$ & 10.72 & .002 \\
\hline Sum $\mathrm{H}$ (index of involvement in social life) & $0.87(9.24)$ & $-0.39(4.31)$ & 40.02 & .001 \\
\hline $\begin{array}{l}\text { Pure } \mathrm{H} \text { (expectations of others - responses associated } \\
\text { with whole human figures) }\end{array}$ & $0.82(4.48)$ & $-0.37(1.59)$ & 32.31 & .001 \\
\hline PER (personal responses) & $-0.22(0.80)$ & $0.16(1.31)$ & 2.35 & .129 \\
\hline ISOL I (isolation index) & $-0.09(0.19)$ & $0.06(0.42)$ & 0.37 & .546 \\
\hline $\begin{array}{l}\text { AG (index of aggressive responses and hostile attitude } \\
\text { towards the social environment) }\end{array}$ & $0.49(2.12)$ & $-0.29(1.09)$ & 11.17 & .001 \\
\hline
\end{tabular}


are based on their own experiences. The individuals display a capacity for gathering feedback from the social environment.

The results of this investigation yielded a few significant findings. It was found that compared with the subjects belonging to cluster 2, the individuals comprising cluster 1 exhibited a greater tendency towards establishing interpersonal relationships, and seemed to be more interested in social life. It was also observed that the subjects in cluster 2 exhibited a significantly lower capacity for cooperation, and decreased interest in social life. The study participants comprising cluster 1 were found to demonstrate the need to establish interpersonal relationships, which was accompanied by a tendency towards perceiving others as aggressive.

\section{SPECIAL INDICES (AGGRESSION, HOSTILITY, DEPRESSIVE TENDENCIES, A SUICIDE CONSTELLATION, EXCESSIVE SUSPICION, PSYCHOTIC PROCESS)}

It was found that the examined individuals in cluster 2 were less vulnerable to depressive tendencies than the subjects in cluster 1 . The values of the other special indices proved to be similar in both samples, and thus no clinical differences were identified between the examined individuals. There was no basis to make a hypothesis that the study participants in both clusters were suffering from psychotic or paranoid personality disorder. Analysis of the research data revealed that the subjects comprising cluster 1 exhibited an increased capacity for establishing interpersonal relationships, and a higher level of maturity in expressing aggressive, self-aggressive and depressive tendencies, compared with the examined individuals in cluster 2 . The evidence from this study suggests that the subjects in cluster 1 display characteristics which are symptomatic of a neurotic level of personality organization, whereas the individuals in cluster 2 seem to be organized at a high borderline level (according to Gabbard's classification).

\section{DISCUSSION}

The findings of the current study are consistent with those of contemporary psychodynamic psychiatrists such as McWilliams (2010), Gabbard (2009), and Clarkin, Fonagy, and Gabbard (2013), who emphasize the importance of specific diagnostic criteria for neurotic and high-level borderline personality disorders in the process of identifying the organization of personality structure. The clinical diagnostic criteria describing a neurotic and borderline level of personality structure, which were put forward by Gabbard, Clarkin and Fonagy, seem to correspond with the constellation of personality characteristics displayed by the study participants in cluster 1 (patients with a neurotic level of personality organization) and the subjects comprising cluster 2 (individuals with a high-level borderline personality organization).

Analysis of the research data revealed that the study participants with a medical diagnosis of neurotic disorders (F40-F41) and the individuals suffering from personality disorders (F60) exhibited no symptoms of more severe destabilization of personality structure, which in Gabbard's classification is referred to as low-level borderline organization of personality structure, and which McWilliams defines as a psychotic level of personality organization. The results of the Rorschach test obtained in both clusters may be explained by the fact that the study population comprised patients with anxiety (neurotic) or personality disorders, who most frequently undergo treatment in mental health outpatient clinics, neurosis treatment centers, neurology clinics, and general public and private health centers, whereas patients with a psychotic (low-level borderline) personality structure, who exhibit specific increased psychopathological symptoms (e.g. excessive aggressive behavior or self-harm), receive inpatient treatment.

The findings of this study also suggest that a large proportion of patients who seek treatment for various somatic or mental disorder symptoms of psychogenic origin are diagnosed with personality disorders. The group comprises predominantly individuals with a neurotic as well as high borderline level of personality organization. This points to the fact that the aforementioned personality disorders seem to be most prevalent in contemporary human populations. However, it is recommended that further research be conducted in a larger sample of Polish patients to confirm the hypothesis.

A psychological diagnosis of personality structure established by the present authors based on their own research findings draws on:

- the fundamental assumptions of object relations theory, which describes the pathomechanism in personality disorders as destabilization of personality structure, and focuses on the significant role of defense mechanisms: archaic (e.g. splitting, projective identification, dissociation, primitive idealization) and neurotic ones (e.g. intellectualization, rationalization, reaction formation, denial) (Kernberg, 1967, 1977);

- psychodynamic conceptions, with particular emphasis on the criteria proposed by Gabbard (2009; Clarkin et al., 2013) and McWilliams (2010). According to the main assumptions of these conceptions, examination of personality structure and characteristics involves assessing the following criteria: 1) level of a person's maintained identity (the sense of self and reality testing), 2) level of defense mechanisms (dominant strategies of coping with stress 
and inner conflicts), 3) reality testing (accepting commonly held beliefs regarding reality), 4) characteristics of interpersonal relations, 5) characteristics of moral functioning - capacity to experience the feeling of guilt. The aforementioned criteria are in line with the criteria of the Big Five theory developed by Costa and McCrae, and do not conflict with the main guidelines regarding diagnosing personality disorders, formulated by the American Psychiatric Association in the DSM-5 classification system.

The indicators of personality structure identified as a result of this research, and classified into two different clusters, describe two fundamental dimensions of human functioning: intrapsychic and interpersonal. It can be assumed that they are likely to facilitate the process of developing appropriate psychotherapeutic treatment for individuals diagnosed with various types of personality disorders. The research data suggest that cluster 1 comprised individuals with a neurotic organization of personality structure, who, compared with the borderline subjects classified into cluster 2, exhibited a higher level of perception and thinking (which proved to be less superficial); they also demonstrated a better capacity to analyze their own experiences and behaviors, and to experience the feeling of guilt. Moreover, the study participants belonging to cluster 1 were found to display a better capacity for adequate modulation of emotions and drives. Intellectualization proved to be the most common defense mechanism adopted by the subjects in cluster 1 . It was also discovered that the subjects comprising cluster 2 tended to resort to splitting. Similar findings were reported by Cooper et al. (1988) and DiNuovo (2000).

\section{CONCLUSIONS}

The results of the present investigation indicate that despite the fact that the examined individuals displayed symptoms of different medical diagnoses (F40 and F60), the subjects comprising cluster 1 exhibit a higher level of personality structure compared with the study participants belonging to cluster 2 . This refers to the characteristics of the interpersonal as well as intrapsychic dimension of personality structure. It was found that the two clusters of study participants were significantly different in terms of the following indicators of the Rorschach variables investigated in the present study:

- identity maturity (thinking and perceiving);

- self-evaluation and capacity for self-reflection (i.e. the ability to gain cognitive and emotional insight);

- responsiveness to stimuli, capacity to act in accord with the needs and demands of the social environment (i.e. the ability to maintain moral norms and to experience the feeling of guilt);

- emotion modulation and control (i.e. the ability to control impulsive emotions and responses);
- interpersonal perception (interpersonal relations, empathy, intimacy, expressing aggression and self-aggression).

As a result of the current research it was possible to develop a model of empirically verified indicators of psychological variables which constitute the major criteria for describing the characteristics of neurotic patients as well as individuals who exhibit symptoms of a more destabilized personality organization that is commonly referred to as borderline personality structure. The criteria may prove useful in the process of selecting the most appropriate form of psychotherapeutic treatment, most frequently provided in outpatient clinics.

Two Rorschach protocols presented below, regarding the data gathered in cluster 1 and 2, illustrate the present research findings.
Application of Rorschach test in clinical diagnosis of personality disorders 


\section{CASE 1 - REPRESENTATIVE OF CLUSTER 1 - NEUROTIC PERSONALITY ORGANIZATION}

A woman, aged 35; professionally active; higher education; married; 1 child; medically diagnosed with anxiety disorder; who had undergone no inpatient psychiatric treatment before.

Responses provided by the examined female - neurotic personality organization

Bernadetta Izydorczyk, Agnieszka Gąska

\section{Free-association phase}

1. Oh my!... a human being. Looks as if he had a head and arms.

2. Some kind of an insect, I reckon.

\section{II}

3. I haven't got the foggiest idea... I guess the white blot may be a dome of some Khmer shrine, 'cause it looks so Asian.

4. < I guess some kind of a rodent? Maybe a hamster? It looks so fluffy; the fur seems to be...

5. ...human lungs

6. A raised thumb, bandaged, blood soaking through it

III

7. Two people. What might they be doing?... I don't know. They may be doing something but I'm not sure yet. They seem to be pulling something on opposite ends as if they wanted to tear it apart.

8. I can see a butterfly.

IV

9. I associate it with a road in the middle of a dark forest.

10. This might be the head of a Chinese dragon seen from above the ground.

$\mathrm{V}$

11. A bat. It is flying straight ahead and not noticing anything.

$\mathrm{VI}$

12. This must be some skin, ripped off from some animal. Perhaps a hoofed mammal.

VII

13. Up here there are 2 children's faces, turned towards one another. And...if these are faces, they have feathers attached at the back of their heads, so they may be pretending to be Indians. They are dancing, with their hands like that (the person demonstrates the posture)

\section{Inquiry phase}

I

1. 'Cause I can see a head and hands. Yes, just like when you stand at attention - legs together and is standing like that.

2. A general shape. Those elements of mandibles made me think so. And the wings, of course. And here is an abdomen.

II

3. The shape reminds me of some Burmese or Khmer shrines.

4. ...it looks like this if you look at it in this way, here you can see ears, and here is fur, looks like hamster's fur.

5. The dark area here.

6. What made me think this way? I think the color. I don't like red, and perhaps that's why I associated it with something negative.

III

7. 'Cause it is a human silhouette, here is a head, arms, abdomen, legs. They are resting their hands on something, but this thing is not in one piece any longer. I can even see high heels now, but these are man's shoes. They are men.

8. The shape of the wings

IV

9. I can see two ruts or grooves here, along this road - just like a forest road. There is a forest around it. You said you could see a dark forest. Yes, the color here is dark.

10. Here might be its eyes and eyelids; here is this part of a mandible. Seems like a view from above. And here are the dragon's whiskers.

$\mathrm{V}$

11. Wings, ears. It reminds me of a bat.

$\mathrm{VI}$

12. Mainly because of the coat color. Usually antelopes are darker on their ridges and lighter on the sides. I can also see a head, neck and the whole abdomen. Skin ripped off and spread. VII

13. Here are feathers, and here is a tuft of hair. It looks so Disney-like. A little nose and a mandible. What makes you say it is hair? I have some associations with this profile. Perhaps I remember it from some fairytale. A neck, a little arm and an abdomen which... 
14. A lampshade. A nice one, which fits in an elegant interior.

15. It looks like a cloud floating cross the sky. Especially here, in the middle of the image.

VIII

16. Here some animal is going, or rather creeping.

\section{IX}

17. Some mask

18. Some human anatomy, perhaps female anatomy...

19. A person with a hat, wearing orange clothes, with some kind of a cap on his or her head. $\mathrm{X}$

20. I can see 2 little creatures; they are holding something in their hands. They might be some fairytale creatures.

21. Perhaps some crab here.
14. I associate it with this because I saw something similar some time ago.

15. Right here. The clouds are not the same color, and here you can see the same. Here, the color is darker, frayed edges, and some sunrays are coming through.

VIII

16. Here is its head, paws and a tail. It seems to me that it is creeping; it somehow sets its paws down carefully, its tail low to the ground. IX

17. Here are eyes

18. Perhaps females, these might be ovaries. It's because of the color.

19. I can clearly see a cap and a human silhouette. $X$

20. These are little creatures - it's because of the color. I can see their tails and hoofs. They are holding something together.

21. Perhaps a crab, it has the shape of a crab, some limbs...

A set of Rorschach signs for the examined female - neurotic personality organization

\begin{tabular}{|c|c|c|c|c|c|c|c|c|c|}
\hline Card no. & $\begin{array}{c}\text { Response } \\
\text { no. }\end{array}$ & Location & $\begin{array}{c}\text { Location } \\
\text { no. }\end{array}$ & Determinants & 2 & Content & $\mathrm{P}$ & $Z$ score & $\begin{array}{l}\text { Special } \\
\text { signs }\end{array}$ \\
\hline \multirow[t]{2}{*}{ I } & 1 & Do & 4 & $M^{p}{ }_{o}$ & & $\mathrm{H}$ & & & \\
\hline & 2 & Wo & & Fo & & A & & 1.0 & \\
\hline \multirow[t]{4}{*}{ II } & 3 & DSo & 5 & $\mathrm{Fu}$ & & Ay & & & \\
\hline & $4<$ & Do & 1 & $\mathrm{FT}_{\mathrm{o}}$ & & A & $P$ & & \\
\hline & 5 & Do & 3 & FC'u & & An & & & \\
\hline & 6 & $\mathrm{D}+$ & 2 & $\mathrm{~m}^{\mathrm{a}} \cdot \mathrm{CF}$ & & $\mathrm{Hd}, \mathrm{BI}$ & & 3.0 & MOR, Per \\
\hline \multirow[t]{2}{*}{ III } & 7 & $\mathrm{D}+$ & 1 & $M_{o}^{a}$ & 2 & $\mathrm{H}, \mathrm{Id}$ & $P$ & 3.0 & $A G$ \\
\hline & 8 & Do & 3 & Fo & & A & & & \\
\hline \multirow[t]{2}{*}{ IV } & 9 & $\mathrm{Dd}_{\mathrm{v} /+}$ & 99 & VF. C' $F_{u}$ & & Ls & & 4.0 & \\
\hline & 10 & Do & 1 & $\mathrm{~F}_{-}$ & & $(\mathrm{Ad})$ & & & \\
\hline V & 11 & Wo & & Fo & & A & $\mathrm{P}$ & 1.0 & \\
\hline VI & 12 & Wo & & FY.m ${ }^{p}{ }_{0}$ & & Ad & & 2.5 & \\
\hline \multirow[t]{3}{*}{ VII } & 13 & $\mathrm{D}+$ & 2 & $M^{\mathrm{a}}{ }_{\mathrm{o}}$ & 2 & $(\mathrm{H}), \mathrm{Ad}$ & $P$ & 3.5 & COP \\
\hline & 14 & DSo & 10 & Fo & & Art, $\mathrm{Hh}$ & $P$ & & Per \\
\hline & 15 & $\mathrm{Dv} /+$ & 1,3 & $\mathrm{~m}^{\mathrm{p}} \cdot \mathrm{YF}_{\mathrm{u}}$ & 2 & $\mathrm{Cl}, \mathrm{Na}$ & & 1.0 & \\
\hline VIII & 16 & Do & 1 & $\mathrm{FM}^{\mathrm{a}}{ }_{\mathrm{o}}$ & & A & & & \\
\hline \multirow[t]{2}{*}{ IX } & 17 & WSo & & Fo & & $(\mathrm{Hd})$, Art & $P$ & 5.5 & \\
\hline & 18 & Do & 4 & $\mathrm{FC}_{-}$ & 2 & An & & & \\
\hline \multirow[t]{3}{*}{$x$} & 19 & $\mathrm{D}+$ & 3 & FCo & & $\mathrm{H}, \mathrm{Cg}$ & $P$ & & $\mathrm{COP}$ \\
\hline & 20 & $\mathrm{D}+$ & 8,14 & $F M^{p} \cdot F_{0}$ & 2 & (A), Id & & $\begin{array}{l}2.5 \\
4.0\end{array}$ & \\
\hline & 21 & Do & 1 & Fo & & A & $\mathrm{P}$ & 4.0 & \\
\hline
\end{tabular}




\section{CASE 2 - REPRESENTATIVE \\ OF CLUSTER 2 - BORDERLINE PERSONALITY ORGANIZATION}

relationships), experiencing violence and self-harm in the past, displaying impulsivity; medically diagnosed with personality disorder.

A woman, aged 27, secondary school education, no children, in a relationship (preceded by short-term

Responses provided by the examined female - borderline personality organization

\section{Free-association phase}

I

Bernadetta Izydorczyk, Agnieszka Gąska reproductive system.

2. Some kind of a moth.
1. It reminds me of a pelvis, a kind of a female

3. $V$ A headless woman. A kind of a cruel woman devouring her own children. She seems to be a person with many faces, who loves power. She has no head and that's why she has no wisdom. She enslaves others and cannot be changed. If you want to free yourself from her, you need to kill her. You can't establish any relationship with this woman.

II

4. A face of a man who has been hurt, who has been a victim of violence. He is screaming. I would say he has a reason to do so.

5. Seems like squatting rabbits, with their paws close to each other.

III

6. V Two male warriors. They are turned away from each other, holding swords in their hands. I would say they are dangerous and piqued, ready to fight.

7. This red thing looks like hanging fetuses. In the middle, a blood-colored pelvis. And these are dead fetuses.

IV

8. Some shoes, legs. Large shoes. Some kind of a worm - here is its head, limbs. I would get $\mathrm{V}$ scared if I saw it. Some kind of a monster, actually.

9. Here is a typical bat. This is my only association. A flying bat. VI

10. Some bear skin.

VII

11. Ovaries.
Inquiry chase

I

1. Yes, such a contour, more or less.

2. The wings, the head and white spots on the wings.

3. V Here is a trunk, a neck without a head. Here you can see a clearly drawn contour of her labia. The spots represent those who she wields power over. She has no head; she follows biological instincts which are not reflective. She is not socialized.

II

4. Here is his mouth, eyes, lower lip, which is bleeding. Why do you associate it with blood? It's because of the color, the spot at the bottom. The opening suggests despair, open mouth, screaming. The dark area looks like facial hair, so it must be a man.

5. Here are the ears, I can clearly see their faces, I mean a neck, a nose, an eye, or rather eyes. The other one has a completely different snout. Looks as if... it was laughing. The one on the right has a different expression, not very happy. They are squatting. They have knees, their paws resting on their toes.

III

6. V Here are their heads, chests. The long object is a sword. They are standing turned away from each other. Why do you think they are dangerous and piqued? The sword is pointed upwards, and they look as if they were getting ready for a duel.

7. It resembles fetuses, here is the umbilical cord. The contour looks like hanging fetuses. And here is the pelvis.

IV

8. Yes, just like a horrible monster. Horrible? Yes. Black, gloomy and large. It has such large legs.

\section{$\mathrm{V}$}

9. Yes. It is flying. So characteristic - ears standing upwards, legs, wings.

VI

10. Here, the contour resembles the skin ripped off a bear.

VII

11. It's the contour, yes, it is coming down here. It seems so. 
VIII

12. Some animal

IX

13. A bonfire, I can see fire. Especially here. Looks like fire and the flames going upwards. The green ones in the foreground, and the fire behind them, behind the green blots.

14. I can't figure out what this red thing is. A piece of meat, some pork chops. A piece of meat or something...

15. A flower.

\section{$X$}

16. A sea... a coral reef.

17. A map.
VIII

12. Look here, it has paws, a tail... one thing on one side and the other thing.

IX

13. First of all, some kind of flames going upwards. As if they were fighting, they are stretching out their arms and fighting. You said flames? Yes, because of the contour and the orange color. It looks as if they are in the background, behind this green thing. This is some kind of grass. It seems that the grass has started burning, too.

14. First of all the color of meat. You can buy such a piece in a shop. A red piece. And here is fat or something. Oh, a piece of meat with a bone.

15. Here are some petals, and this is something that the flower springs from, and here are some buds. The whole blot looks like a flower.

$\mathrm{X}$

16. Those colors and contours.

17. A kind of an irregular line... oblong in shape, perhaps a map of some continent.
Application of Rorschach test in clinical diagnosis of personality disorders

A set of Rorschach signs for the examined female - borderline personality organization

\begin{tabular}{|c|c|c|c|c|c|c|c|c|c|}
\hline Card no. & $\begin{array}{c}\text { Response } \\
\text { no. }\end{array}$ & Location & $\begin{array}{c}\text { Location } \\
\text { no. }\end{array}$ & Determinants & 2 & Content & $\mathrm{P}$ & $Z$ score & $\begin{array}{l}\text { Special } \\
\text { signs }\end{array}$ \\
\hline \multirow[t]{3}{*}{ I } & 1 & Wo & & Fo & & An & & 1.0 & \\
\hline & 2 & WSo & & FC'o & & $A$ & & 3.5 & \\
\hline & $3 \mathrm{~V}$ & W+ & & $M^{\mathrm{p}} \mathrm{u}$ & 2 & $\begin{array}{c}\mathrm{H}, \mathrm{Hx}, \mathrm{Sx} \\
\mathrm{Fd}\end{array}$ & & 4.0 & $\begin{array}{c}\text { MOR, AG, } \\
\text { DR1 } \\
\text { (projective } \\
\text { identifica- } \\
\text { tion) }\end{array}$ \\
\hline \multirow[t]{2}{*}{ II } & 4 & WS+ & & $M^{\mathrm{a}} \cdot \mathrm{m}^{\mathrm{p}} \cdot \mathrm{C} \cdot \mathrm{TF}$ & & $\mathrm{Hd}, \mathrm{Bl}, \mathrm{Hx}$ & & 4.5 & \\
\hline & 5 & $\mathrm{D}+$ & 6 & $F M^{\mathrm{p}} \mathrm{O}$ & & $\mathrm{A}, \mathrm{Hx}$ & $\mathrm{P}$ & 3.0 & $\begin{array}{c}\text { MOR, AG } \\
\text { Past } \\
\text { (Splitting) }\end{array}$ \\
\hline \multirow[t]{2}{*}{ III } & 6 & $\mathrm{D}+$ & 9 & $\mathrm{M}^{\mathrm{p}} \mathrm{u}$ & 2 & $\mathrm{H}, \mathrm{Sc}, \mathrm{Hx}$ & $\mathrm{P}$ & 3.0 & \\
\hline & 7 & Do & 2,3 & $M^{p} . F C u$ & 2 & $\mathrm{Hd}, \mathrm{An}, \mathrm{Bl}$ & & & $\begin{array}{c}\text { AG } \\
\text { (projective } \\
\text { identifica- } \\
\text { tion) }\end{array}$ \\
\hline IV & 8 & Wo & & $\mathrm{C}^{\prime} \mathrm{Fu}$ & & $(\mathrm{H}), \mathrm{Cg}$ & & 2.0 & MOR \\
\hline $\mathrm{V}$ & 9 & Wo & & $\mathrm{FM}_{\mathrm{o}}^{\mathrm{a}}$ & & A & $\mathrm{P}$ & 1.0 & \\
\hline $\mathrm{VI}$ & 10 & Do & 1 & Fo & & $\mathrm{Ad}$ & $\mathrm{P}$ & & MOR, Per \\
\hline VII & 11 & Wo & & $\mathrm{F}_{-}$ & & An, Sx & & 2.5 & \\
\hline VIII & 12 & Do & 1 & Fo & 2 & A & $\mathrm{P}$ & & \\
\hline \multirow[t]{3}{*}{ IX } & 13 & $\mathrm{Dv} /+$ & 11,12 & $\mathrm{~m}^{\mathrm{a}}$.C.FD+ & & $\mathrm{Fi}, \mathrm{Bt}$ & & 2.5 & \\
\hline & 14 & $\mathrm{Dv} /+$ & 6 & C & & $\mathrm{Fd}$ & & 2.5 & \\
\hline & 15 & Wv & & Fo & & $\mathrm{Bt}$ & & & \\
\hline$X$ & 16 & $\mathrm{Wv} /+$ & & CFo & & $\mathrm{Na}$ & & 5.5 & $\mathrm{AG}$ \\
\hline
\end{tabular}




\section{REFERENCES}

Biagiarelli, M., Roma, P., Comparelli, A., Paola, M., Di Pomponio, I., Corigliano, V., Curto, M., Allison, G. McLean, M., \& Ferracuti, S. (2015). Relationship between the Rorschach Perceptual Thinking Index (PTI) and the Positive and Negative Syndrome Scale (PANSS) in psychotic patients: a validity study. Psychiatry Research, 225, 315-321.

Bilash, I. S. (2011). An investigation of the relationship between empathy and the human movement

Bernadetta Izydorczyk, Agnieszka Gąska response on the Rorschach test. Dissertation Abstracts International: Section B: The Sciences and Engineering, Vol. 72 (5-B), 3128. US: ProQuest Information \& Learning. 0419-4217 (in print).

Bram, A. D. (2010). The relevance of the Rorschach and patient-examiner relationship in treatment planning and outcome assessment. Journal of Personality Assessment, 92, 91-115. doi: 10.1080/00223890903508112

Chabert, C. (1987). La psychopatologie a l'epreuve du Rorschach [The psychopathology the test of Rorschach]. Paris: Dunod.

Charnas, J.W., Hilsenroth, M. J., Zodan, J. \& Blais, M. A. (2010). Should I stay or should I go? Personality Assessment Inventory and Rorschach indices of early withdrawal from psychotherapy. Psychotherapy, 47, 484-499.

Clarkin, J. F., Fonagy, P., \& Gabbard, G. O. (2013). Psychoterapia psychodynamiczna [Psychodynamic psychotherapy]. Kraków: Wydawnictwo Uniwersytetu Jagiellońskiego.

Cooper, S. H., Perry, J. C., \& Arnow, D. (1988). An empirical approach to the study of defense mechanisms: I. reliability and preliminary validity of the Rorschach Defense Scale. Journal of Personality Assessment, 52, 183-203.

Czerederecka, A. (2006). Test Rorschacha w psychologicznej ekspertyzie sądowej [Application of the Rorschach test in forensic psychological evaluation]. Krakow: Wydawnictwo Instytutu Ekspertyz Sądowych IES.

De Tichey, C. (1982). Test de Rorschach et mechanisms de defense dans les 'etats-limites' [Rorschach test and the defense mechanism in borderline disorders]. Psychologie Medicale, 14, 1965-1874.

Diener, M. J., Hilsenroth, M. J., Shaffer, S. A., \& Sexton, J. E. (2011). A meta-analysis of the relationship between the Rorschach Ego Impairment Endex (EII) and psychiatric severity. Clinical Psychology \& Psychotherapy, 18, 464-485.

Di Nuovo, S. (2000). A diagnosis of the borderline personality disorder by means of the Rorschach test. Przeglad Psychologiczny, 43, 101-114.

Dulz, B., \& Schneider, A. (1997). Borderline-Störungen. Theorie und Therapie [Borderline disorders. Theory and therapy]. Stuttgart: Schattauer Verlagsgesellschaft.

Exner, J. E. (1974). The Rorschach: A Comprehensive System. New York: Wiley.

Exner, J. E. (1978). The Rorschach: A Comprehensive System. Vol. 2: Recent research and advanced interpretation. New York: Wiley.

Exner, J. E. (1986). Some Rorschach data comparing schizophrenics with borderline and schizotypal personality disorders. Journal of Personality Assessment, 50, 455-471.

Fellers, G. L. (2012). A study of the relationships between selected Rorschach variables and neuroticism and extraversion. Dissertation Abstracts International: Section B: The Sciences and Engineering 72 (5-B), 3128, US: ProQuest Information \& Learning, ISSN: 0419-4217.

Gabbard, G. O. (2009). Psychiatria psychodynamiczna w praktyce klinicznej [Psychodynamic psychiatry in clinical practice]. Kraków: Wydawnictwo Uniwersytetu Jagiellońskiego.

Gacono, C. B., Meloy, J. R, \& Berg, J. L. (1992). Object relations, defensive operations, and affectivestates in narcissistic, borderline and antisocial personality disorder. Journal of Personality Assessment, 55, 270-279.

Gacono, C. B., \& Meloy, J. R. (1997). The Rorschach research and psychodiagnostic of antisocial and psychopathic personalities. Rorschachiana, 22, 130-148.

Grabski, B., \& Gierowski, K. (2012). Zaburzenia osobowości - różne spojrzenia i próby ich integracji [Personality disorders - different outlooks and attempts at their integration]. Psychiatria Polska, $46,829-844$.

Izydorczyk, B., \& Gąska, A. (2015). Application of psychological diagnosis in the process of establishing criteria for psychodynamic therapy designed for patients with personality disorders. Archives of Psychiatry and Psychotherapy, 4, 5-16.

Jordan, R. J. (2012). Use of the Rorschach and MMPI-2 in Distinguishing Pedophilic and Teleiophilic Sexual Offenders. Dissertation Abstracts International: Section B: The Sciences and Engineering, 73 (4-B), 2505. US: ProQuest Information \& Learning.

Kernberg, O. F. (1967). Borderline personality organization. Journal of the American Psychoanalytic Association, 15, 641-685.

Kernberg, O. F. (1977). The structural diagnosis of borderline personality organization. In P. Hartocollis (ed.), Borderline personality disorders. The concept, the syndrome, the patient (pp. 87-121). New York: International Universities Press.

Kwawer, J., Lerner, H., Lerner, P., \& Sugarman, A. (1980). Borderline phenomena and the Rorschach test. New York: International Universities Press.

Łuszczyńska-Cieślak, A., \& Cieślak, R. (1996). Minnesocki Wielowymiarowy Inwentarz Osobowości [The Minnesota Multidimensional Personality Inven- 
tory]. Encyklopedia Badań Medycznych. Gdańsk: Wydawnictwo Medyczne MAKmed.

McCrae, R. R., \& Costa, P. T. (2005). Osobowość dorostego człowieka: perspektywa teorii pięcioczynnikowej [A five-factor theory perspective on adult personality]. Kraków: Wydawnictwo WAM.

McWilliams, N. (2010). Diagnoza psychoanalityczna [Psychoanalytic diagnosis]. Gdańsk: Gdańskie Wydawnictwo Naukowe GWP.

Paluchowski, W. J. (1984). Stosowanie i interpretacja kwestionariusza MMPI [Application and interpretation of the MMPI inventory]. Warszawa: PTP.

Shafer, T. W., Erdberg, P., \& Meyer, G. (2007). Introduction to the JPA Special Supplement on International Reference Samples for the Rorschach Comprehensive System. Journal of Personality Assessment, 2, 2-6. doi: 10.1080/00223890701629268

Siuta, J. (2006). NEO-PI-R - Inwentarz Osobowości NEOPI-R P. T. Costy Jr i R. R. McCrae [The NEO-PI-R inventory by P.T Costa \& R. R. McCrae]. Warszawa: Pracownia Testów Psychologicznych PTP.

Stasiakiewicz, M. (2004). Test Rorschacha [The Rorschach test]. Warszawa: Wydawnictwo Naukowe Scholar.

The status of the Rorschach in Clinical and Forensic Practice: an official statement by the Board of Trustees of the Society for Personality Assessment (2005). Journal of Personality Assessment, 85, 219-237.

Waszkiewicz, E., \& Zakrzewska-Wirkus, K. (2012). Test Rorschacha w diagnostyce klinicznej i badaniach międzykulturowych [Application of the Rorschach test in a clinical diagnosis and cross-cultural studies]. Psychiatria i Psychoterapia, 8, 21-36.

Xian-Zhang, M., \& Ting-Ye, L. (2015). Differences of Ego Impairment Index of Rorschach test between patients with schizophrenia and normal individuals. Chinese Mental Health Journal, 29, 522-527.

Yazigi, L., Semer, N., de Carvalho, A. T., de Mattos Fiore, M. L., da Silva, J., Freitas R., \& Botelho, N. (2011). Rorschach and the WAIS-III after one and two years of psychotherapy. Psicologia: Reflexão $e$ Crítica, 24, 10-18.

Zodan, J., Hilsenroth, M. J., Charnas, J., Goldman, R., \& Bornstein, R. (2014). Rorschach assessment of childhood sexual abuse severity, borderline pathology, and their interaction: An examination of criterion validity. Psychological Trauma: Theory, Research, Practice, and Policy, 6, 318-327. 